\title{
The effect of standard heat and filtration processing procedures on antimicrobial activity and hydrogen peroxide levels in honey
}

\author{
Cuilan Chen ${ }^{1}$, Leona T. Campbell', Shona E. Blair ${ }^{1,2}$ and Dee A. Carter ${ }^{1 *}$ \\ 1 School of Molecular Bioscience, University of Sydney, Sydney, NSW, Australia \\ 2 School of Biotechnology and Biomolecular Sciences, University of New South Wales, Sydney, NSW, Australia
}

Edited by:

Pedro I. Da Silva Jr., Butantan

Institute, Brazil

Reviewed by:

Mirian A. F. Hayashi, Universidade

Federal de São Paulo, Brazil

Katrina Brudzynski, Brock University,

Canada

\section{*Correspondence:}

Dee A. Carter, School of Molecular

Bioscience, University of Sydney,

Sydney, NSW 2006, Australia.

e-mail:dee.carter@sydney.edu.au

\begin{abstract}
There is increasing interest in the antimicrobial properties of honey. In most honey types, antimicrobial activity is due to the generation of hydrogen peroxide $\left(\mathrm{H}_{2} \mathrm{O}_{2}\right)$, but this can vary greatly among samples. Honey is a complex product and other components may modulate activity, which can be further affected by commercial processing procedures. In this study we examined honey derived from three native Australian floral sources that had previously been associated with $\mathrm{H}_{2} \mathrm{O}_{2}$-dependent activity. Antibacterial activity was seen in four red stringybark samples only, and ranged from 12 to $21.1 \%$ phenol equivalence against Staphylococcus aureus. Antifungal activity ranged from MIC values of 19-38.3\% (w/v) against Candida albicans, and all samples were significantly more active than an osmotically equivalent sugar solution. All honey samples were provided unprocessed and following commercial processing. Processing was usually detrimental to antimicrobial activity, but occasionally the reverse was seen and activity increased. $\mathrm{H}_{2} \mathrm{O}_{2}$ levels varied from 0 to $1017 \mu \mathrm{M}$, and although samples with no $\mathrm{H}_{2} \mathrm{O}_{2}$ had little or no antimicrobial activity, some samples had relatively high $\mathrm{H}_{2} \mathrm{O}_{2}$ levels yet no antimicrobial activity. In samples where $\mathrm{H}_{2} \mathrm{O}_{2}$ was detected, the correlation with antibacterial activity was greater in the processed than in the unprocessed samples, suggesting other factors present in the honey influence this activity and are sensitive to heat treatment. Antifungal activity did not correlate with the level of $\mathrm{H}_{2} \mathrm{O}_{2}$ in honey samples, and overall it appeared that $\mathrm{H}_{2} \mathrm{O}_{2}$ alone was not sufficient to inhibit $C$. albicans. We conclude that floral source and $\mathrm{H}_{2} \mathrm{O}_{2}$ levels are not reliable predictors of the antimicrobial activity of honey, which currently can only be assessed by standardized antimicrobial testing. Heat processing should be reduced where possible, and honey destined for medicinal use should be retested post-processing to ensure that activity levels have not changed.
\end{abstract}

Keywords: honey, Australia, Staphylococcus aureus, Candida albicans, hydrogen peroxide, heat treatment

\section{INTRODUCTION}

Honey has been widely used for thousands of years, not only in food and beverages but also for treating diseases (Blair and Carter, 2005). As a complex natural product, there are a variety of factors that contribute to the antimicrobial activity of honey. The primary antimicrobial component in most honeys is hydrogen peroxide $\left(\mathrm{H}_{2} \mathrm{O}_{2}\right)$, which is produced by the bee-derived enzyme glucose oxidase (White et al., 1963). Certain honey types contain additional antimicrobial activity, which has been attributed to various different components including methylglyoxal (MGO), bee defensin-1, and other bee-derived compounds, florally derived phenolics, lysozyme, and other yet undetermined compounds (Estevinho et al., 2008; Irish et al., 2008; Mavric et al., 2008; Adams et al., 2009; Kwakman et al., 2010, 2011). Antimicrobial activity derived from these components has been grouped together and is generally referred to in the literature as "non-peroxide dependent" activity (Blair and Carter, 2005).

Honey is broad-spectrum and active against a range of different bacteria and fungi (Molan, 1992, 2009). Transcriptome and proteome studies on how bacteria respond to treatment have found honey to have a unique and multimodal mode of action (Blair et al., 2009; Packer et al., 2012). In addition, unlike most antibiotics, resistance to honey cannot be induced (Blair et al., 2009). These features make honey an attractive alternative treatment, particularly for topical application to skin and mucosal membranes (English et al., 2004; Chambers, 2006; Molan, 2006b).

Australia has a diverse, unique natural flora, and honey production is a multi-million dollar industry. Although predominantly destined for table use, some antimicrobial Australian honey is also produced and marketed. Recently, a survey of the antibacterial properties of honey derived from a wide range of Australian plants was undertaken that demonstrated the potential of Australian floral sources for the production of medicalgrade honey (Irish et al., 2011). As well as finding $\mathrm{H}_{2} \mathrm{O}_{2}$ - and MGO-type activity, this study found some honey samples had antimicrobial activity that was clearly different to known peroxide and non-peroxide activities. 
The current study was undertaken to follow up some of the native Australian honeys investigated by Irish et al. (2011) in order to determine whether some of the more promising floral sources would produce consistently active honey, and to assess if new, as yet undefined non-peroxide activities could be identified. During the course of honey testing we were provided with samples that were completely unprocessed, and with aliquots of the same honey samples that undergone heating and filtration procedures used in the honey industry to remove wax and particulate matter and to prevent granulation. Heat treatment is relatively mild ( $\sim 45^{\circ} \mathrm{C}$ for up to $8 \mathrm{~h}$ ) and does not appear to affect MGO levels (Matheson and Murray, 2011) but might affect enzymes such as glucose oxidase or other non-peroxide factors. Since antimicrobial testing is generally conducted on raw, unprocessed honey, but heat and filtration are required to process honey, we were interested to see how antimicrobial activity was affected by these methods. Finally, as the addition of catalase reduced the antimicrobial activity in all samples to insignificant levels and there was no apparent non-peroxide activity, we assessed the levels of $\mathrm{H}_{2} \mathrm{O}_{2}$ to determine how this correlated with antimicrobial potency.

\section{MATERIALS AND METHODS HONEY SAMPLES}

All honeys were sourced and supplied by Beechworth Honey (Corowa, NSW, Australia) and are listed in Table 1. Honey derived from three native Australian floral sources were tested, with five independent samples of each. These included spotted gum (Eucalyptus maculata) (samples S1-S5), red stringybark (Eucalyptus macrorrhyncha) (samples R1-R5), and yellow box (Eucalyptus melliodora) (samples Y1-Y5). One mixed sample of canola/red stringybark (R6) and one pure sample of canola honey (Brassica napus) (C1) were also included. It should be noted that the identified plants only represent the major source of honey for that sample; honeys are rarely derived from only one species, and other floral sources may contribute to any one batch. An artificial honey ( $7.5 \mathrm{~g}$ sucrose, $37.5 \mathrm{~g}$ maltose, $167.5 \mathrm{~g}$ glucose, and $202.5 \mathrm{~g}$ fructose in $85 \mathrm{~mL}$ sterile water) was used to simulate osmotic factors due to the high sugar level in honey. Comvita $\mathrm{UMF}^{\circledR} 18+$ manuka honey (Te Puke, New Zealand) was used as a positive control in the phenol equivalence assay.

\section{HONEY TREATMENT}

"Unprocessed" and "processed" versions of each honey sample were supplied and tested. The unprocessed samples were supplied directly as they had been obtained from beekeepers and had not undergone any heating or filtration. Processed aliquots of each of the same honey samples had been subjected to standard commercial treatment at Beechworth Honey, which involved heating the bulk honey purchase to $45^{\circ} \mathrm{C}$ for $8 \mathrm{~h}$ and filtering with a $100 \mu \mathrm{m}$ filter.

Immediately prior to antimicrobial tests, all honey samples were diluted and filtered through a $0.2 \mu \mathrm{m}$ fliter (Millipore) in the laboratory to eliminate contaminating micro-organisms. For the assessment of non-peroxide activity, catalase (Sigma-Aldrich, USA) was added to samples at a final concentration of $2800 \mathrm{U} / \mathrm{mL}$ prior to testing.

\section{ASSESSMENT OF ANTIBACTERIAL ACTIVITY}

The antibacterial activity of honey samples was assessed using the standard method described by Allen et al. (1991a). This measures the inhibition of Staphylococcus aureus strain ATCC 25923 (Oxoid, Hampshire, UK) by honey in an agar well diffusion assay and reports activity as equivalence to dilutions of phenol. Briefly, an $18 \mathrm{~h}$ culture of $S$. aureus grown in tryptone soy broth (TSB) was adjusted to 0.5 at $\mathrm{A}_{540} \mathrm{~nm}$ (approx. $5 \times 10^{7}$ cells $/ \mathrm{ml}$ ). One hundred and fifty $\mathrm{mL}$ of molten, cooled nutrient agar (BD Difco, USA) was seeded with $100 \mu \mathrm{L}$ of the prepared S. aureus culture and poured into a large square bioassay plate $(245 \times 245 \mathrm{~mm}$; Corning). Plates were stored inverted at $4^{\circ} \mathrm{C}$ for use the next day, when wells were cut into the agar with a sterile $8 \mathrm{~mm}$ diameter cork borer. Each well was numbered, in duplicate, using a quasi-Latin square, which enabled duplicate samples to be placed randomly on the plate.

Fifty percent $(w / v)$ of each honey sample, including the Comvita and the artificial honey, were prepared fresh for each assay in sterile deionized water, and incubated at $37^{\circ} \mathrm{C}$ with shaking at $200 \mathrm{rpm}$ for $30 \mathrm{~min}$ to aid mixing. Diluted honey samples were then filter sterilized through $0.2 \mu \mathrm{m}$ pore filters (Millipore) and mixed with equal volumes of either sterile deionized water for total activity testing, or freshly prepared $5600 \mathrm{U} / \mathrm{mL}$ catalase solution (Sigma-Aldrich, USA) for non-peroxide activity testing, to give a final concentration of $25 \%(\mathrm{w} / \mathrm{v})$ honey. Aliquots of $100 \mu \mathrm{L}$ of each solution were placed into wells of the assay plates.

Phenol (Sigma-Aldrich, USA) standards of 2, 3, 4, 5, 6, and $7 \%$ were prepared from a $10 \% \mathrm{w} / \mathrm{v}$ solution that was freshly made every four weeks in sterile deionized water and stored at $4^{\circ} \mathrm{C}$. Aliquots of $100 \mu \mathrm{L}$ of each phenol dilution were placed in duplicate wells of the assay plates. Artificial honey, sterile deionized water and catalase solution were included as negative controls. The plates were incubated at $37^{\circ} \mathrm{C}$ for $18 \mathrm{~h}$.

The diameter of each zone of inhibition was measured using Vernier calipers. The mean diameter of the zone of inhibition around each well was squared, and a phenol standard curve was generated with phenol concentration against the mean squared diameter of the zone of inhibition. The activity of each honey sample was calculated using the standard curve. To account for the dilution and density of honey, this figure was multiplied by 4.69 (based on a mean honey density of $1.35 \mathrm{~g} / \mathrm{mL}$, as determined by Allen et al. (1991b), and the activity of the honey was then expressed as the equivalent phenol concentration (\% w/v). Each honey sample was tested on at least three separate occasions, and the mean phenol equivalence was recorded.

\section{ASSESSMENT OF ANTIFUNGAL ACTIVITY}

As there is no standardized method for assessing the antifungal activity of honey, this was done using the CLSI (formerly NCCLS) microdilution method with some modifications as described by Irish et al. (2006). This method, which has been developed to assess minimum inhibitory concentrations (MICs) of antibiotics, was used to assess the MIC of each honey against Candida albicans ATCC 10231 (Oxoid, Hampshire, UK). Briefly, honey samples were prepared by the addition of RPMI1640 medium (Sigma-Aldrich, USA) to make 50\% (w/v) stock 


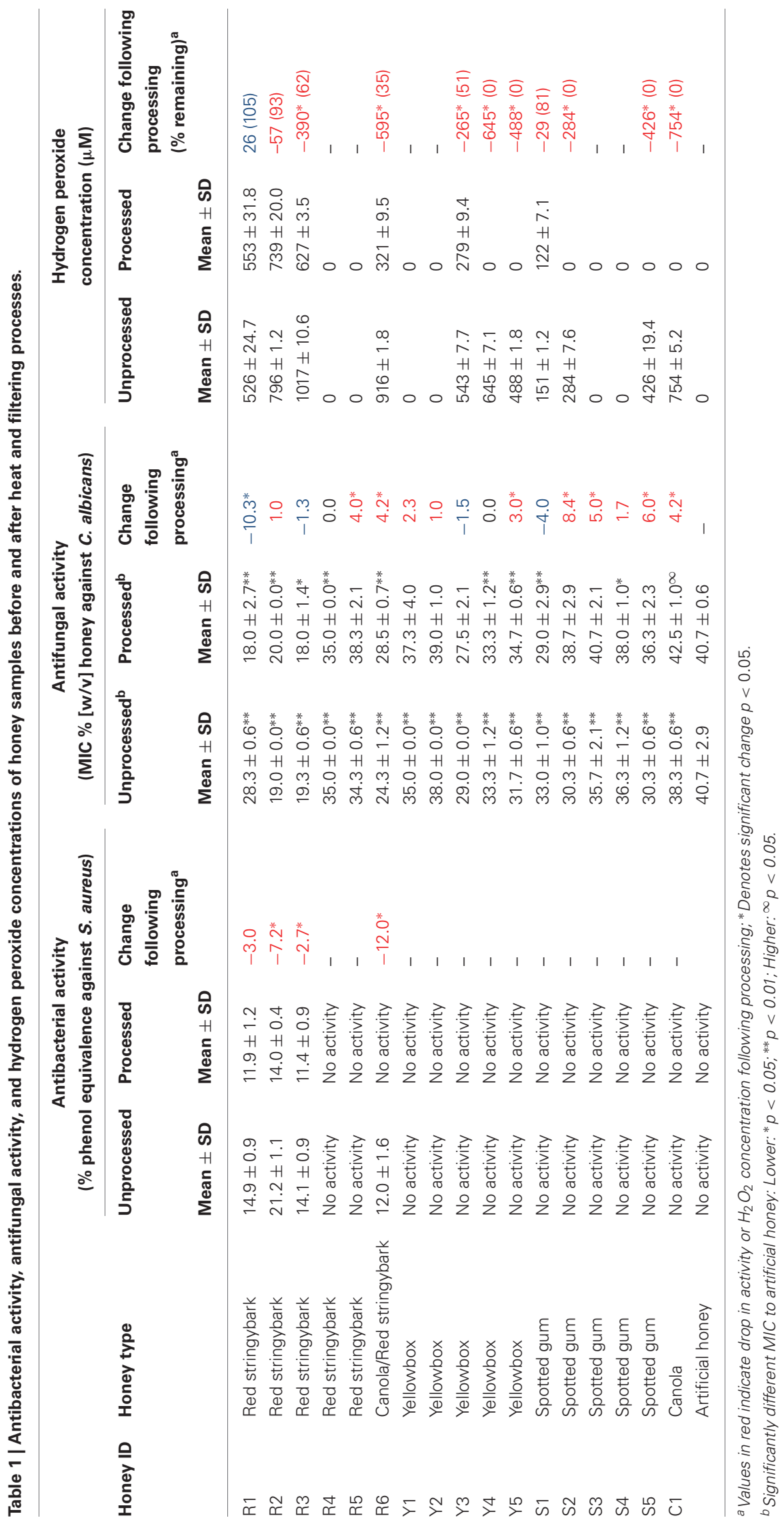


solutions and incubated at $37^{\circ} \mathrm{C}$ with shaking at $200 \mathrm{rpm}$ for $30 \mathrm{~min}$ to aid mixing. The diluted honey solutions were filter sterilized through $0.2 \mu \mathrm{m}$ pore filters (Millipore) and further diluted with RPMI-1640 medium in 96-well U-bottomed microtitre plates to give final honey concentrations in $1 \%(\mathrm{w} / \mathrm{v})$ increments from 10 to $50 \%$. Artificial honey was included as an osmotic control.

C. albicans cultures were prepared by picking five colonies from an overnight yeast peptone dextrose agar plate and suspending them in $5 \mathrm{~mL} 0.85 \%$ saline. Transmittance of the culture was measured at $530 \mathrm{~nm}$ and adjusted to $0.8-0.88$. Adjusted cultures were diluted 1:50 in sterile $0.85 \%$ saline, then further diluted 1:4 in RPMI-1640 medium, to achieve a working concentration of $5 \times 10^{3}$ to $2.5 \times 10^{4} \mathrm{cfu} / \mathrm{mL}$. Twenty-five $\mu \mathrm{L}$ of the diluted culture was added to each well of the microtitre plate, resulting in a final inoculum of 0.5 to $2.5 \times 10^{3} \mathrm{cfu} / \mathrm{mL}$. Growth controls (no honey added) and sterility controls (RPMI-1640 medium only and honey solution only) were included in each plate. Following incubation at $35^{\circ} \mathrm{C}$ for $24 \mathrm{~h}$, the MIC was recorded as the lowest concentration of honey that prevented growth, which was assessed visually. Each honey sample was tested in duplicate and the assays were repeated on at least three separate occasions, with the mean MIC recorded.

\section{HYDROGEN PEROXIDE ASSAY}

The concentration of $\mathrm{H}_{2} \mathrm{O}_{2}$ in honey samples was determined using a colorimetric assay that has previously been used to measure $\mathrm{H}_{2} \mathrm{O}_{2}$ in honey (Kwakman et al., 2010). Fifty percent (w/v) honey solutions were made by the addition of sterile deionized water to the honey samples. Samples were incubated at $37^{\circ} \mathrm{C}$ with shaking at $200 \mathrm{rpm}$ for $30 \mathrm{~min}$ to aid mixing. The diluted honey solutions were filter sterilized through $0.2 \mu \mathrm{m}$ pore filters (Millipore, USA) and further diluted to $25 \%(\mathrm{w} / \mathrm{v})$ by mixing with either sterile deionized water or $5600 \mathrm{U} / \mathrm{mL}$ catalase solution (Sigma-Aldrich, USA). Aliquots of $40 \mu \mathrm{L}$ of each honey sample were added to wells of a 96-well flat-bottomed microtiter plate in triplicate. $\mathrm{H}_{2} \mathrm{O}_{2}$ (Sigma-Aldrich, USA) standards ranging from 2.1 to $2200 \mu \mathrm{M}$ were made by 2 -fold serial dilutions and $40 \mu \mathrm{L}$ of each standard was added to the plates. Sterile deionized water and catalase solution were also included as negative controls.

The reagent mixture consisting of $50 \mu \mathrm{g} / \mathrm{mL}$ of $\mathrm{O}$-dianisidine (Sigma-Aldrich, USA) and $20 \mu \mathrm{g} / \mathrm{mL} \mathrm{H}_{2} \mathrm{O}_{2}$ type IV (SigmaAldrich, USA) in $10 \mathrm{mM}$ phosphate buffer ( $\mathrm{pH}$ 6.5), was freshly made from stock solutions of $1 \mathrm{mg} / \mathrm{mL}$ stock of $O$-dianisidine and $10 \mathrm{mg} / \mathrm{mL}$ of horseradish peroxidise type IV. One hundred and thirty-five $\mu \mathrm{L}$ of this reagent mixture was added to wells of the microtiter plate containing the honey samples and $\mathrm{H}_{2} \mathrm{O}_{2}$ standards prepared as outlined above. Following incubation for $5 \mathrm{~min}$ at room temperature, reactions were stopped by the addition of $120 \mu \mathrm{L} 6 \mathrm{M} \mathrm{H}_{2} \mathrm{SO}_{4}$. The color of the reaction was measured by absorbance at $560 \mathrm{~nm}$ using a Multiskan Ex plate reader (Thermo Scientific, USA), and $\mathrm{H}_{2} \mathrm{O}_{2}$ concentrations were calculated using a standard curve derived from the $\mathrm{H}_{2} \mathrm{O}_{2}$ standards. Each honey sample was tested in triplicate and assays were repeated on three separate occasions, giving a total of nine readings per honey sample.

\section{STATISTICAL ANALYSIS}

Statistical analysis of the data was performed using IBM SPSS Statistics 19 software. Differences between the activity of the honey samples and the artificial honey were evaluated using the independent samples $t$-test. This test was also used to compare the activity of the different honey types. Correlation analysis was done using Spearman's Rank Correlation with an online tool available at http://www.wessa.net (Wessa, 2011).

\section{RESULTS}

ANTIBACTERIAL ACTIVITY OF RAW AND PROCESSED HONEY SAMPLES

Four out of the 17 unprocessed honey samples (35\%) had detectable antibacterial activity against $S$. aureus (Table 1). Activity in these samples was eliminated following the addition of catalase, and none exhibited detectable non-peroxide activity (data not shown). The four active honeys were red stringybark samples R1, R2, R3, and R6, and these had phenol equivalence values ranging from 12.0 to $21.2 \%(\mathrm{w} / \mathrm{v})$. Following heat treatment and filtration, antibacterial activity was detected in only three red stringybark samples, and these were all significantly lower than the corresponding unprocessed honey samples. Activity was completely lost from sample R6, the red stringybark/canola blend (Table 1).

\section{ANTIFUNGAL ACTIVITY OF RAW AND PROCESSED HONEY SAMPLES}

All of the unprocessed honey samples had significantly higher antifungal activity than the artificial honey sample $(p<0.05$; Table 1), however, this was also reduced to insignificant levels following catalase treatment (data not shown). The majority of the unprocessed honey samples had high MICs, corresponding to low antifungal activity, with 12 of the 17 honeys exhibiting MICs $>30 \%$ (Table 1). Only two of the honeys (R2 and R3) had MICs $<20 \%$ and three of the honeys (R1, R6, and Y3) had MICs $<30 \%$.

Most of the processed honey samples also had lower antifungal activity than the unprocessed honeys, and only nine samples remained more active than the artificial honey (Table 1). However, in red stringybark sample R1 the reverse was seen, and the processed sample was significantly more active than its unprocessed counterpart.

\section{EFFECT OF PROCESSING ON THE PRODUCTION OF HYDROGEN PEROXIDE}

$\mathrm{H}_{2} \mathrm{O}_{2}$ was measured in the honey samples before and after processing to determine how this was affected by heat processing. Eleven of the 17 unprocessed honey samples produced detectable $\mathrm{H}_{2} \mathrm{O}_{2}$ (Table 1). Four of the unprocessed red stringybark honey samples (R1, R2, R3, and R6) had among the highest $\mathrm{H}_{2} \mathrm{O}_{2}$ concentrations, which was consistent with the high antibacterial and antifungal activity seen in these samples However, $\mathrm{H}_{2} \mathrm{O}_{2}$ was also produced in unprocessed yellow box (Y3, Y4, and Y5), spotted gum (S1, S2, and S5) and canola honey (C1) samples that did not have any detectable antibacterial activity.

Correlation analysis using Spearman's Rank Correlation indicated that $\mathrm{H}_{2} \mathrm{O}_{2}$ production and antibacterial activity in the unprocessed honey samples was positively correlated (rho $=0.64$; $p=0.005)$. However, this appeared to be driven by the samples 
with no $\mathrm{H}_{2} \mathrm{O}_{2}$ production, which also showed no antibacterial activity (samples R4, R5, Y1, Y2, S3, and S4). When these were removed from the analysis, correlation was lost (rho $=0.59$, $p=0.056)$. In contrast, in the processed samples $\mathrm{H}_{2} \mathrm{O}_{2}$ production and antibacterial activity were strongly correlated across the entire dataset (rho $=0.77 ; p=0.0002$ ), and this remained (albeit reduced) when processed samples without $\mathrm{H}_{2} \mathrm{O}_{2}$ were excluded ( $r h o=0.88 ; p=0.02$ ). These results suggest one or more components are present in the unprocessed honey samples that modulate the inhibition of bacteria by $\mathrm{H}_{2} \mathrm{O}_{2}$, and these are sensitive to heat processing.

Antifungal activity was strongly correlated with $\mathrm{H}_{2} \mathrm{O}_{2}$ production in both the processed and the unprocessed samples $(p<0.005)$. However, this correlation was again lost when samples with no $\mathrm{H}_{2} \mathrm{O}_{2}$ production were removed from the analysis (rho $=-0.53, p=0.096$; and rho $=-0.71, p=0.11$ for unprocessed and processed samples, respectively).

Detectable $\mathrm{H}_{2} \mathrm{O}_{2}$ production remained in only six of the 17 honey samples following processing (Table 1). Red stringybark honeys R1, R2, R3, and R6 had the highest levels of $\mathrm{H}_{2} \mathrm{O}_{2}$, however, processing affected their $\mathrm{H}_{2} \mathrm{O}_{2}$ production differently, with a significant reduction seen in samples $\mathrm{R} 3$ and $\mathrm{R} 6$ but no significant change in samples $\mathrm{R} 1$ and $\mathrm{R} 2 . \mathrm{H}_{2} \mathrm{O}_{2}$ was no longer produced by the majority of the processed yellow box and spotted gum samples, and it was undetectable in samples Y4, Y5, S5, and $\mathrm{C} 1$, which all had high $\mathrm{H}_{2} \mathrm{O}_{2}$ levels before processing yet had no detectable antibacterial activity. Overall, while it was apparent that heating the honeys negatively affected $\mathrm{H}_{2} \mathrm{O}_{2}$ production, the extent to which this happened varied in the different honey samples. Within the subset of samples where $\mathrm{H}_{2} \mathrm{O}_{2}$ was produced, there was no correlation between the amount produced before and after processing ( rho $=0.46 ; p=0.15$ ).

\section{DISCUSSION}

There is increasing recognition of the value of medicinal honey, both as a high-value product that can be produced commercially in many parts of the world, including in rural and resourcepoor settings, and as a potently active medicine that is effective against antibiotic-resistant pathogens. However, the parameters surrounding the reliable production of medicinally active honey remain poorly understood. Antimicrobial assays are usually performed on raw, unprocessed honey that is diluted and filtered to eliminate microorganisms prior to testing but is not heat-treated (Irish et al., 2011), but this may not be accurate if the honey must be heated subsequently to filter out particulate debris. In the current study, we assessed the antimicrobial properties of a number of independent samples of three common Australian honeys and investigated the effect of mild processing using heating and filtering methods that are routine for commercial honey production. In addition, as the current microbiological tests for antimicrobial activity are relatively labor-intensive, we analyzed whether floral source or $\mathrm{H}_{2} \mathrm{O}_{2}$ levels might be useful predictors of antimicrobial activity.

\section{RED STRINGYBARK: A USEFUL FLORAL SOURCE FOR MEDICINAL HONEY?}

Honey produced from native Australian flora has the potential for therapeutic use, firstly because a number of floral sources produce active honey (Lusby et al., 2005; Irish et al., 2011), and secondly because many Australian native forests occur in relatively remote areas that are likely to be free from pesticides and pollutants that could be introduced into the honey during production (Feás and Estevinho, 2011). Among the honeys selected for this study, some red stringybark samples displayed antibacterial activity at a potentially therapeutically useful level (Table 1; Molan, 1999). In a large-scale survey undertaken by Irish et al. (2011), different red stringybark samples had similar, relatively high antibacterial activities. However, in the current study there were large variations in activity among the different red stringybark samples. Similarly, although Irish et al. found Australian spotted gum honeys had antibacterial activity [median of $18.9 \%(\mathrm{w} / \mathrm{v})$ phenol equivalence], none of the spotted gum samples in the current study showed activity. The current findings, and those from other studies (Allen et al., 1991a; Al-Jabri et al., 2003; Irish et al., 2011), indicate that while floral source is an important determinant of antimicrobial activity, it remains difficult to use this to predict the antimicrobial properties of a given honey sample. Therefore, while this work suggests that red stringybark could be a useful floral source for the production of medically active honey, the inconsistency among samples means individual samples still need to be screened for activity.

\section{HYDROGEN PEROXIDE PRODUCTION IS NOT ALWAYS SUFFICIENT FOR ANTIMICROBIAL ACTIVITY}

As antimicrobial activity was reduced to insignificant levels when the honey samples were treated with catalase it was assumed that the production of $\mathrm{H}_{2} \mathrm{O}_{2}$ was responsible for most or all of the observed activity. In honey, glucose oxidase, which is secreted from the hypopharyngeal glands of bees, breaks down glucose to form gluconic acid and $\mathrm{H}_{2} \mathrm{O}_{2}$. Lack of free water and an acidic $\mathrm{pH}$ renders glucose oxidase inactive, but activity is restored when the honey is diluted with water, providing a slow, sustained release of $\mathrm{H}_{2} \mathrm{O}_{2}$, at sufficient levels to produce an antimicrobial effect but not high enough to damage mammalian tissues (Bang et al., 2003). In the current study, honey was diluted four-fold, which is optimal for $\mathrm{H}_{2} \mathrm{O}_{2}$ production from most honey types (Brudzynski et al., 2011).

Although there was a high level of correlation between the level of $\mathrm{H}_{2} \mathrm{O}_{2}$ produced by honey samples and their level of antibacterial and antifungal activity, which is consistent with other reports (White et al., 1963; Taormina et al., 2001; Brudzynski, 2006), this was lost once samples without any detectable $\mathrm{H}_{2} \mathrm{O}_{2}$ were excluded from the analysis; the only exception being the processed honey samples and their antibacterial activity. This suggests that $\mathrm{H}_{2} \mathrm{O}_{2}$ alone may not be sufficient for antimicrobial activity: honey samples with little or no $\mathrm{H}_{2} \mathrm{O}_{2}$ have a correspondingly low ability to inhibit bacteria and fungi, but if present, the level of $\mathrm{H}_{2} \mathrm{O}_{2}$ and the degree to which the honey is antimicrobial do not necessarily correlate. Indeed, some samples, such as canola honey $\mathrm{C} 1$ and yellowbox honey $\mathrm{Y} 4$ had particularly high $\mathrm{H}_{2} \mathrm{O}_{2}$ levels (754 and $645 \mu \mathrm{M}$, respectively) yet no antibacterial activity and very low antifungal activity, while sample R1 had $526 \mu \mathrm{M} \mathrm{H}_{2} \mathrm{O}_{2}$, but was among the most active of the honey samples. 
Other studies have found that the level of $\mathrm{H}_{2} \mathrm{O}_{2}$ present in honey is more than 900-fold lower than expected based on the level of antimicrobial activity, and it has been suggested that there are one or more synergents present in honey that augment the action of $\mathrm{H}_{2} \mathrm{O}_{2}$ (Molan, 2006a; Kwakman et al., 2010; Brudzynski et al., 2011). It is possible that these synergents do not occur in samples where $\mathrm{H}_{2} \mathrm{O}_{2}$ was produced but little or no activity was seen. Alternatively, there may be other, as yet undefined compounds present in the inactive honey samples that interfere with the antimicrobial activity of $\mathrm{H}_{2} \mathrm{O}_{2}$. An interesting area of further study would be to compare the components present in honey samples with very different levels of antimicrobial activity but similar $\mathrm{H}_{2} \mathrm{O}_{2}$ levels (e.g., red stringybark sample $\mathrm{R} 2$ vs. canola honey $\mathrm{C} 1$ ), which may allow these possible synergents or agonists to be identified.

\section{STANDARD PROCESSING REDUCES THE ANTIMICROBIAL PROPERTIES OF HONEY BUT EFFECT VARIES AMONG SAMPLES}

Processed honey samples had on average lower antifungal and antibacterial activity. Average antibacterial levels in the active samples (R1, R2, R3, and R6) dropped from 15.6 to 9.3\% phenol equivalence. A significant reduction was seen in all but sample R1, and in sample R6, the red stringybark/canola blend, activity was lost altogether. Similarly, the average antifungal MIC changed from 31 to $33 \%$, and for the canola honey $\mathrm{C} 1$, the MIC became significantly higher than for the artificial honey (Table 1; $p<0.05)$, indicating that this honey has less antifungal activity than an osmotically equivalent sugar solution. The change to antifungal activity following processing varied considerably among the different samples: only seven of the 17 samples dropped significantly in activity, nine were unchanged and in sample R1 the activity level significantly increased, with the MIC changing from 28.6 to $18 \%(\mathrm{w} / \mathrm{v})$ post-processing.

Heating above physiological temperatures is generally detrimental to enzymes, and a previous study on glucose oxidase in honey found that heating at $50^{\circ} \mathrm{C}$ for $20 \mathrm{~min}$ significantly reduced enzyme activity (Schepartz and Subers, 1964; White and Subers, 1964). Although most honey samples tested in the current study produced less $\mathrm{H}_{2} \mathrm{O}_{2}$ after heat treatment, with some dropping to zero, in others there was no significant difference before or after treatment, and overall there was no correlation between the level of $\mathrm{H}_{2} \mathrm{O}_{2}$ across the different honey samples preand post-heat treatment. Of interest is that while high levels of $\mathrm{H}_{2} \mathrm{O}_{2}$ were seen in some of the unprocessed samples that had no detectable antibacterial activity, only the active red stringybark samples (R1, R2, and R3) retained high (>500 $\mu \mathrm{M}) \mathrm{H}_{2} \mathrm{O}_{2}$ levels post-processing. With only these three stably active samples, the current dataset is too small to derive robust conclusions. However, it is possible that the stability of $\mathrm{H}_{2} \mathrm{O}_{2}$ production is important in determining the activity of a honey sample, and a honey that loses the ability to produce $\mathrm{H}_{2} \mathrm{O}_{2}$ following standard heat processing could lose useful therapeutic activity, even if $\mathrm{H}_{2} \mathrm{O}_{2}$ levels prior to processing were high. Further investigation of this is warranted as a test to predict antibacterial activity based on $\mathrm{H}_{2} \mathrm{O}_{2}$ stability would be very helpful to the honey industry, and $\mathrm{H}_{2} \mathrm{O}_{2}$ levels alone appear to be a poor indicator of final activity levels.
The level of glucose oxidase in honey can vary depending on the health of the bees and the quality of their diet (Pernal and Currie, 2000; Alaux et al., 2010). However, the amount of $\mathrm{H}_{2} \mathrm{O}_{2}$ produced in a given honey sample is not determined by glucose oxidase alone, as honey can also contain catalase, peroxidases, and antioxidants such as gallic acid and caffeic acid that can degrade $\mathrm{H}_{2} \mathrm{O}_{2}$ or interfere with its ability to damage microbial cells (Weston, 2000; Al-Mamary et al., 2002; Sroka and Cisowski, 2003; Yao et al., 2003; Pyrzynska and Biesaga, 2009). In addition, it was recently reported that MGO directly modifies some proteinacious compounds in honey and if present this may also affect glucose oxidase activity (Majtan et al., 2012). The final level of $\mathrm{H}_{2} \mathrm{O}_{2}$ in a given honey sample therefore depends on various components, which can be present and active to varying degrees. Since any of these may be affected by honey processing, it is not unexpected that the different honey samples responded quite differently to heat treatment.

All commercial table honey is filtered to remove particulate debris, and heating up to $45^{\circ} \mathrm{C}$ is regularly used to increase the rate of filtration, but it is important to recognize that even relatively mild heat processing can reduce antimicrobial activity. Honey viscosity does not change appreciably above $\sim 30^{\circ} \mathrm{C}$ (Matheson and Murray, 2011) and lower processing temperatures may be possible without a significant increase in inconvenience. Other studies have noted a reduction in enzymes, antioxidants and other phytonutrients following processing (Blasa et al., 2006; Turkmen et al., 2006; Ropa, 2010), and again this can vary considerably among samples. Minimal processing is therefore advisable for honey produced for medicinal purposes, and samples should be tested post-processing to ensure antimicrobial activity is not significantly reduced.

\section{HONEY: A COMPLEX NATURAL PRODUCT}

The complexity of natural products, including honey, makes them very difficult to standardize and this can affect their acceptance in clinical medicine. However, this complexity also has benefits. Unlike conventional antibiotics it appears to be difficult for microorganisms to become resistant to the effects of honey, probably due to the action of the various active components in honey on multiple microbial targets (Blair et al., 2009). An increasing interest in honey has led to recent studies that have begun to unravel how honey affects microbes at the cellular and molecular levels (Blair et al., 2009; Brudzynski et al., 2011; Kwakman et al., 2011; Kwakman and Zaat, 2012; Packer et al., 2012). New, advanced statistical methods for analyzing complex relationships may also help us to understand this complex process (Reshef et al., 2011). As well as developing a wider acceptance of selected honeys in conventional antimicrobial therapy, further studies could reveal lead compounds for the development of novel antimicrobials, which are urgently required.

\section{CONCLUSIONS}

We conclude from this study that floral source and $\mathrm{H}_{2} \mathrm{O}_{2}$ levels, while important in determining the antimicrobial properties of honey, cannot be used to reliably predict whether 
a given honey sample will have antibacterial or antifungal activity. In general, processing with heat and filtration reduces $\mathrm{H}_{2} \mathrm{O}_{2}$-based activity but this varies in different honey samples. The most active honey samples produced high levels of $\mathrm{H}_{2} \mathrm{O}_{2}$ both before and after heating, suggesting $\mathrm{H}_{2} \mathrm{O}_{2}$ stability could be a useful indicator of antimicrobial activity, but further research with a greater number of samples is required to support this observation. The potentially detrimental effects of even mild heating should be taken into account

\section{REFERENCES}

Adams, C. J., Manley-Harris, M., and Molan, P. C. (2009). The origin of methylglyoxal in New Zealand manuka (Leptospermum scoparium) honey. Carbohydr. Res. 344, 1050-1053.

Al-Jabri, A., Nzeako, B., Al Mahrooqi, Z., Al Naqdy, A., and Nsanze, H. (2003). In vitro antibacterial activity of Omani and African honey. Br. J. Biomed. Sci. 60, $1-4$.

Al-Mamary, M., Al-Meeri, A., and Al-Habori, M. (2002). Antioxidant activities and total phenolics of different types of honey. Nutr. Res. 22, 1041-1047.

Alaux, C., Ducloz, F., Crauser, D., and Leconte, Y. (2010). Diet effects on honeybee immunocompetence. Biol. Lett. 6, 562-565.

Allen, K. L., Molan, P. C., and Reid, G. M. (1991a). A survey of the antibacterial activity of some New Zealand honeys. J. Pharm. Pharmacol. 43, 817-822.

Allen, K. L., Molan, P. C., and Reid, G. M. (1991b). The variability of the antibacterial activity of honey. Apiacta 26, 114-121.

Bang, L. M., Buntting, C., and Molan, P. C. (2003). The effect of dilution on the rate of hydrogen peroxide production in honey and its implications for wound healing. J. Altern. Complement. Med. 9, 267-273.

Blair, S. E., and Carter, D. A. (2005). The potential for honey in the management of wound and infection. J. Aust. Inf. Contr. 10, 24-31.

Blair, S. E., Cokcetin, N., Harry, E., and Carter, D. A. (2009). The unusual antibacterial activity of medical-grade Leptospermum honey: antibacterial spectrum, resistance and transcriptome analysis. Eur. J. Clin. Microbiol. Infect. Dis. 28, 1199-1208.

Blasa, M., Candiracci, M., Accorsi, A., Piacentini, M. P., Albertini, M. C., and Piatti, E. (2006). Raw Millefiori honey is packed full of antioxidants. Food Chem. 97, 217-222.
Brudzynski, K. (2006). Effect of hydrogen peroxide on antibacterial activities of Canadian honeys. Can. J. Microbiol. 52, 1228-1237.

Brudzynski, K., Abubaker, K., StMartin, L., and Castle, A. (2011). Re-examining the role of hydrogen peroxide in bacteriostatic and bactericidal activities of honey. Front. Microbiol. 2:213. doi: 10.3389/ fmicb.2011.00213

Chambers, J. (2006). Topical manuka honey for MRSA-contaminated skin ulcers. Palliat. Med. 20, 557-558.

English, H., Pack, A., and Molan, P. (2004). The effects of manuka honey on plaque and gingivitis: a pilot study. J. Int. Acad. Periodontol. 6,63 .

Estevinho, L., Pereira, A. P., Moreira, L., Dias, L. G., and Pereira, E. (2008). Antioxidant and antimicrobial effects of phenolic compounds extracts of Northeast Portugal honey. Food Chem. Toxicol. 46, 3774-3779.

Feás, X., and Estevinho, M. L. (2011). A survey of the in vitro antifungal activity of heather (Erica Sp.) organic honey. J. Med. Food 14, 1284-1288.

Irish, J., Blair, S. E., and Carter, D. A. (2011). The antibacterial activity of honey derived from Australian flora. PLoS ONE 6:e18229. doi: 10.1371/journal.pone.0018229

Irish, J., Carter, D. A., Blair, S. E., and Heard, T. A. (2008). Antibacterial activity of honey from the Australian stingless bee Trigona carbonaria. Int. J. Antimicrob. Agents 32, 89-90.

Irish, J., Carter, D. A., Shokohi, T., and Blair, S. E. (2006). Honey has an antifungal effect against Candida species. Med. Mycol. 44, 289-291.

Kwakman, P. H. S., Te Velde, A. A., De Boer, L., Speijer, D., Vandenbroucke-Grauls, C. M. J. E., and Zaat, S. A. J. (2010). How honey kills bacteria. FASEB J. 24, 2576.

Kwakman, P. H. S., Te Velde, A. A., De Boer, L., Vandenbroucke-Grauls, C.

when processing and testing honey destined for medicinal use.

\section{ACKNOWLEDGMENTS}

We thank Dr. David Dall and Professor Joan Dawes of Pestat Pty Ltd for helpful discussions on this project and for sourcing honey samples, and Beechworth Honey for providing the honey samples. This work was supported by Rural Industries R\&D Corporation project grant PRJ-005590.

M. J. E., and Zaat, S. A. J. (2011). Two major medicinal honeys have different mechanisms of bactericidal activity. PLoS ONE 6:e17709. doi: 10.1371/journal.pone.0017709

Kwakman, P. H. S., and Zaat, S. A. J. (2012). Antibacterial components of honey. IUBMB Life 64, 48-55.

Lusby, P. E., Coombes, A. L., and Wilkinson, J. M. (2005). Bactericidal activity of different honeys against pathogenic bacteria. Arch. Med. Res. 36, 464-467.

Majtan, J., Klaudiny, J., Bohova, J., Kohutova, L., Dzurova, M., Sediva, M., Bartosova, M., and Majtan, V. (2012). Methylglyoxal-induced modifications of significant honeybee proteinous components in manuka honey: possible therapeutic implications. Fitoterapia 83, 671-677.

Matheson, A., and Murray, R. (2011). Practical Beekeeping in New Zealand, 4th Edn. Auckland, New Zealand: Exisle Publishing Limited.

Mavric, E., Wittmann, S., Barth, G., and Henle, T. (2008). Identification and quantification of methylglyoxal as the dominant antibacterial constituent of Manuka (Leptospermum scoparium) honeys from New Zealand. Mol. Nutr. Food Res. 52, 483-489.

Molan, P. C. (1992). The antibacterial activity of honey: 2. Variation in the potency of the antibacterial activity. Bee World 73, 59-76.

Molan, P. C. (1999). The role of honey in the management of wounds. J. Wound Care 8, 423-426.

Molan, P. C. (2006a). The antibacterial activity of honey: 1 . The nature of the antibacterial activity. Bee World 73, 5-28.

Molan, P. C. (2006b). The evidence supporting the use of honey as a wound dressing. Int. J. Low. Extrem. Wounds 5, 40.

Molan, P. C. (2009). "Honey: antimicrobial actions and role in disease management," in New Strategies Combating Bacterial Infection, eds I. Ahmad and F. Aqil (Weinheim: Wiley VCH), 229-253.
Packer, J. M., Irish, J., Herbert, B. R., Hill, C., Padula, M., Blair, S. E., Carter, D. A., and Harry, E. J. (2012). Specific non-peroxide antibacterial effect of manuka honey on the Staphylococcus aureus proteome. Int. J. Antimicrob. Agents 40, 43-50.

Pernal, S. F., and Currie, R. W. (2000). Pollen quality of fresh and 1-year-old single pollen diets for worker honeybees (Apis mellifera L.). Apidologie 31, 387-409.

Pyrzynska, K., and Biesaga, M. (2009). Analysis of phenolic acids and flavonoids in honey. Trends Anal. Chem. 28, 893-902.

Reshef, D. N., Reshef, Y. A., Finucane, H. K., Grossman, S. R., McVean, G., Turnbaugh, P. J., Lander, E. S., Mitzenmacher, M., and Sabeti, P. C. (2011). Detecting novel associations in large data sets. Science 334, 1518-1524.

Ropa, D. (2010). Comparison of Mineral and Enzyme Levels in Raw and Processed Honey. Wisconsin: Ropa Science Research.

Schepartz, A. I., and Subers, M. H. (1964). The glucose oxidase of honey I. Purification and some general properties of the enzyme. Biochim. Biophys. Acta 85, 228-237.

Sroka, Z., and Cisowski, W. (2003). Hydrogen peroxide scavenging, antioxidant and anti-radical activity of some phenolic acids. Food Chem. Toxicol. 41, 753-758.

Taormina, P. J., Niemira, B. A., and Beuchat, L. R. (2001). Inhibitory activity of honey against foodborne pathogens as influenced by the presence of hydrogen peroxide and level of antioxidant power. Int. J. Food Microbiol. 69, 217-225.

Turkmen, N., Sari, F., Poyrazoglu, E. S., and Velioglu, Y. S. (2006). Effects of prolonged heating on antioxidant activity and colour of honey. Food Chem. 95, 653-657.

Wessa, P. (2011). Free Statistics Software. Office for Research Development and Education. Available online at: http://www. wessa.net [Accessed October 2011]. 
Weston, R. J. (2000). The contribution of catalase and other natural products to the antibacterial activity of honey: a review. Food Chem. 71, 235-239.

White, J. W., and Subers, M. H. (1964). Studies on honey inhibine. 3. Effect of heat. J. Apic. Res. 3, 45-50.

White, J. W., Subers, M. H., and Schepartz, A. I. (1963). The identification of inhibine, the antibacterial factor in honey, as hydrogen peroxide and its origin in a honey glucose-oxidase system. Biochim. Biophys. Acta 73, 57-70.

Yao, L., Datta, N., Tomás-Barberán, F. A., Ferreres, F., Martos, I., and Singanusong, R. (2003). Flavonoids, phenolic acids and abscisic acid in Australian and New Zealand Leptospermum honeys. Food Chem. 81, 159-168.

Conflict of Interest Statement: The authors declare that the research was conducted in the absence of any commercial or financial relationships that could be construed as a potential conflict of interest.

Received: 23 March 2012; paper pending published: 03 April 2012; accepted: 05 July 2012; published online: 27 July 2012. Citation: Chen C, Campbell LT, Blair SE and Carter DA (2012) The effect of standard heat and filtration processing procedures on antimicrobial activity and hydrogen peroxide levels in honey. Front. Microbio. 3:265. doi: 10.3389/ fmicb.2012.00265
This article was submitted to Frontiers in Antimicrobials, Resistance and Chemotherapy, a specialty of Frontiers in Microbiology.

Copyright (C) 2012 Chen, Campbell, Blair and Carter. This is an openaccess article distributed under the terms of the Creative Commons Attribution License, which permits use, distribution and reproduction in other forums, provided the original authors and source are credited and subject to any copyright notices concerning any third-party graphics etc. 